\title{
A Global Perspective on Controlling West Nile Virus Identifying Efficient and Effective Public Health Strategies
}

\author{
Fatih Sekercioglu and Stella Triboi
}

\section{ABSTRACT}

\begin{abstract}
West Nile Virus has been an increased concern for many countries over the past couple of decades. We examine West Nile Virus surveillance strategies around the world and identify West Nile Virus control methods in endemic countries and demonstrate their effectiveness and efficiency. Despite the ample amount of research, monitoring and control methods conducted by public health agencies, West Nile Virus remains a continuous health threat tothe public. Countries that report West Nile Virus cases are identified and searched for articles and national protocols to explore their strategies in controlling the virus. It is essential to discuss all methods of prevention in a global context and demonstrate the most efficient and effective strategy. Datawere collected from published articles on PubMed and governmental websites.All the documents were selected upon descriptive surveillance and control methods in endemic countries. The generated data were identified and compared to Center for Disease Control and Prevention recommendations. Thorough details about West Nile Virus control methods were identified in Canada and the United States, while strategies in the endemic countries are sparse. There is a substantial lack of published data in some endemic countries. Therefore, it is suggested that public health agencies publish the strategies found to be most efficient and effective and share them at an international level. This paper provides reference to public health agencies ata global level to strengthen the interventions in controlling the West Nile Virus.
\end{abstract}

Keywords: Mosquito Control, Mosquito Surveillance, Public Health Strategies of West Nile Virus, West Nile Virus Prevention.

\author{
Submitted : July 16, 2021 \\ Published : August 28, 2021 \\ ISSN: $2593-8339$ \\ DOI: $10.24018 /$ ejmed.2021.3.4.1032 \\ Fatih Sekerciolgu* \\ Assistant Professor, School of \\ Occupational and Public Health, \\ Ryerson University, Toronto, Canada. \\ (e-mail: fsekercioglu@ryerson.ca) \\ Stella Triboi \\ School of Occupational and Public \\ Health, Ryerson University, Toronto, \\ Canada. \\ (e-mail: stella.triboi @ ryerson.ca)
}

*Corresponding Author

\section{INTRODUCTION}

West Nile Virus (WNV) is a vector-borne infection transmitted by mosquitoes that can cause severe neurological disease and death in humans. World Health Organization (WHO) states that presentlythis infection exists on several continents and regions such as Africa, Europe, the Middle East, the Americas, and West Asia and is considered a significant threat to human health. WNV was first discovered in Uganda in 1937 in humans, and since then, plenty of outbreaksaround the world have occurred [1]. The pathogenic picture of WNV in the zoonotic field had not raised concern until1997 when the infected birds that presented symptoms of encephalitis and paralysis in Israel were found positive for WNV [1]. Countries reported by WHO to have suffered significant outbreaks areGreece, Israel, Romania, Russia, the United States, Canada, Venezuela [1]. This infection represents an important public health issue that requires a solid surveillance system to be put in placeworldwide.

Nations with reported outbreaks are assumed to implement national surveillance programs to mitigate the public health risk of infection. The Center for Disease Control and Prevention (CDC) recommends these programs tohave wellfounded epidemiological objectives that address mosquito abundance and infection rate in thecommunity. To reach the goal and prove effectiveness, such programs should include criteria solidifying theirapplicability and reliability. Firstly, WNV surveillance programs should be sustainable for more extended periods to collect sufficient data that will assist the public health agencies in identifying trends and make comparisons in the end [2]. Secondly, operational activities mustbe consistent and regularly executed(weekly), and the mosquito sample collection should be carried out at fixed sites [2]. Respecting these rules will lead to a better understanding of WNV activity and infection rate in a community. It willhelp create a strategic plan that works fora specific area.

Our paper aims to review the WNV control strategies globally and provide references for public health agencies to develop efficient and effective WNV programs. The study identifies the endemic countries that have shared their strategic plans and discuss the control programs of these countries. In addition, a comparison between the Canadian and international approaches will be providedto elucidate the best operations of such programs. 


\section{WNV PROGRAM COMPONENTS}

World Health Organization plays a significant worldwide role in WNV surveillance and outbreak response.Because of high infection rates in Europeand the Americas, WHO has established partnerships with countries in these two continents to better assist the WNV global response [1]. It is well known that the fundamental keys in the WNV mitigation process are prevention, vector surveillance and control methods. These interventions, which will be further discussed, represent best practices worth following to mitigate the WNV risk. However, each endemic country possesses its own strategy according to the national/provincial allocated funds oreffectiveness observed over the length ofresearch and various studies

\section{A. Vector Surveillance}

Mosquito surveillance is an active method of vector surveillance program proposed by CDC [2]. This is part of the Integrated Vector Management (IVM) program and is meant to provide detailed information about the seasonalmosquito population, identify the infection rate in high-risk geographic areas, implement intervention activities when needed and assess the effectiveness of the control measures[2]. Such a program implicates mosquito collection, which requirestraps with specific functions. Nasci et al. [2] describe the following types of traps that can be used in WNV surveillance programs and thedrawbacks some of them may have. Host seeking mosquitos (Culex tarsalis, Culex pipiens, Culex quinquefasciatus - active at night) traps represent CDC miniature light traps featured with batteries to supply the light and fan withpower and $\mathrm{CO} 2$ (dry ice) to bait the mosquitos. These traps are the most used, although some limitations regarding the accuracy of the infection rate of WNV in the case of a smallsample have been reported. Mosquitoes that carry eggs usually seek habitats with stagnant water where they can lay the eggs. The traps used for these vectors are called gravid traps, which possess attractants like dry grass infusion, fish oil, or cow manure to imitate the stagnant water smell and lurethe mosquitoes. Gravid traps are less frequently used by surveillance programs due to their capacity to capture only Culex pipiens species, which consequently provides insufficient data about the prevalent species in the community. Restingmosquito collection is performed by use of suction traps and handheld or backpack mechanical aspirators; the sampled vectors are a good source of population representation in the geographic area and an important indicator of infection rates. Nevertheless, due to the manualhandling of these devices, an extensive effort may be needed to collect the mosquitos, which might result in a smaller and irrelevant sample.

After collecting the samples, placing the mosquitos in cooler boxes with dry ice is recommended to optimize the laboratory testing by preserving the virusmorphology [2]. To increase the sensitivity of vector testing, the pooling of 50100 specimens is required, each one categorized by date, species, and location[2]. Only female mosquitoes are tested for WNV [2].

\section{B. Bird Surveillance}

Bird surveillance is a passive method of determining the presence and activity of WNV in a geographic area, which also delivers information about the index of risk for the residents. Reports on dead birds are mainly done by the public through educational campaigns. This is an area that necessitates continuous public education and motivation to keep them informed about WNV activity in the community and the implications it can have on their health. Losing the public interest and engagement in bird surveillance programs may result in failure to report the dead birds, as well as decreasing the accuracy of WNV data in the region. It is worth noting that some birds gain a lifelong immunity after contracting the virus and recovering from it, which makes them resistant to the pathogen [3]. In such events, serology tests to detect antibodies in juvenile birdsare suggested, along with studies on seroconversion in adult birds.

Live bird surveillance implies living birds as sentinels, which provides valuable information about the transmissibility of $\mathrm{WNV}$ in the region. Most tested are captive chickens, and usually, a count of 6-10 birds is being sampled for blood work during the virus transmission season. There are two essential aspects worth mentioning. Firstly, data indicates that serology testing on sentinel chickens proved WNVtransmission to birds' weeks before humancases were reported [2]. However, some studies argue the importance of this statement, demonstrating that human cases do not regularly follow cases ofinfected sentinel birds [3]. Secondly, serology surveys of amplifier hosts provide information about the prevalent mosquito species in the community and can help the program to create maps that identify the high-risk zones.

Moreover, serosurveys may provide insights about host immunity and seek WNV antibodies. More levels of detected antibodies suggest less viral amplification, which can be explained by the vertical transmission of maternal antibodies to offspring. This data can contribute to an early WNV prediction ina geographic area [2].

Horses can be drastically affected by WNV as well, providing the encephalopathy symptoms they can develop. Suggestions on using them as sentinel have been made, yet the successful outcome of the vaccination program on horses outweighs the purposeof the proposed plan.

\section{Control Method}

IVM is a program that aims to mitigate WNV activity in a geographic area and applies the principles of integrated pesticide management. Thorough understanding of mosquitoes' nature and WNV transmission levels, IVM interventions can decrease the infection rate in a community by reducing the vector levels in breeding sites. To attain optimal results of the program, two procedures that complement each other intheir objectives and final goal must be considered, such as larval and adult mosquito control.

Larval control refers to source reduction and aims to spot and monitor the vector's breeding sites, such as ponds, artificial containers, or ditches. Trained staff is to identify the larvae and to determine the instar and population number. To keep the levels down, lessen the virus amplification in the host and reduce the risk of human infection, the larval population must be prevented from emerging into adults. This process can bestopped by using larvicides in theirbreeding habitats. The larvicides come indifferent formulations like liquid,granules, pellets, tablets, and briquets andare applied 
by trained technicians that usetracks and backpack sprayers or aircraft- mounted sprayers [5].

The abundance of mosquito bites and the interruption of WNV transmission in birds can be controlled by using adulticides that treat the adult mosquito habitats, which can be applied by truck- mounted sprayers or aircraft. Like larvicides, the adulticides must beregistered by EPA, and the treatment application relies on ultra-low volume sprays that disperse droplets to kill the flying mosquitoes. This treatment method may include any of the following formulations:organophosphate insecticides (malathion and naled) or synthetic pyrethroid insecticides (prallethrin, etofenprox, pyrethrins, permethrin, resmethrin, sumithrin) [5].

To demonstrate the effectiveness of larval and adult mosquito control,evaluation of the treated sites must be performed at least once in three months. This ensures if the quality of the applied treatment is satisfactory, and no insecticide resistance is developing.

\section{Control Method}

It is essential to prevent the spread of the vector in the community by developing educational programs to acknowledge the presence of the virusand communicate its activity, gravity, and the risks it has on residents' health. Thorough explanations about WNV emerging sources should be provided to all community members, along withactions to be taken during the seasonswith high transmission rates. In addition to outdoors avoidance during mosquito high activity hours, public health professionals should advise the targeted audience about the importance of practicing personal protection. CDC recommends using conventionalrepellents like DEET or Picaridin and biopesticides repellents like Oil of Lemon Eucalyptus, PMD or IR3535 [2]. Another crucial element of community-based prevention is source reduction, which canbe accomplished by regularly clearing thestanding water from trash containers, tires, toys, rain gutters, paddling pools, buckets, or flowerpots [2].

\section{WNV - INTERVENTIONS - ACROSS THE GLOBE}

\section{A. Europe}

European Center for Disease Prevention and Control (ECDC) established a WNV preparedness framework based on entomological surveillance in high-risk areas, which aims to identify the virus circulation and develop effective control programs.Interventions applied in this regard include larvae and mosquito collectionusing established traps in specific areas [6].

Greece is one of the European countriesthat faced a large epidemic in 2010, following which the first national entomological surveillance was created [7]. According to the author of this study, the national program was conducted over a period of three years following CDC recommendations, which included the setting of CDC light traps with CO2, BGSentinel/Mosquitaire and triple traps in the high-risk areas of Central Macedonia. It is mentioned in the study that the number of traps had increased gradually, providing the program extended its trapping zones from North to South Greece. The efficacy of the study was demonstrated by the significant correlation found between the most identified mosquito species, Culexpipiens and Ochlerotatus caspius, andWNV human cases over the study period. In their study, Chantoutis et al. [8] discuss another surveillance program conducted in Greece, whichcomplimented the mosquito traps with serology tests performed on chickens and looked for antibodies against WNV. Surprisingly, seropositivity in chickenscorrelated with 11 new cases of WNVdisease, which demonstrates the goodefficacy of such surveillance systems indetecting WNV. Seropositivity studies inchickens and the link between these and the high incidence rate of WNV in humancases were supported by other articles [9]-[12]. In addition, serological assays to detect antibodies were successfully attempted in pigeons as well, which showed a remarkable association betweenseroprevalence in these birds and highhuman infectious rate in rural areas ofCentral Macedonia [13]. The author of this study suggests that domestic pigeonscould be a reliable and cost-effective toolin WNV monitoring. Given that theseroprevalence in birds was factual, it wasconcluded that WNV might have overwintered in endemic areas in Greece [9].

Romania is another Eastern European country that was hit by a major WNV epidemic in 1996, which drove the authorities to establish a surveillance system to protect the public [14], [15]. The proposed program included human, entomological and bird surveillance. Mosquito collection involved the use of handheld and backpack aspirators in the resting areas inside the buildings, while inthe vegetation sites near rivers and nesting areas sweep-nets were used.Carbon dioxide baited traps are being used in recent years in the endemic zones[16]. Seroprevalence of $\mathrm{IgG}$ antibodies was tested on domestic fowl (ducks, geese, chickens, and turkeys) and wild birds located in the proximity of the residential areas of the positive human cases; a link between seropositivity on birds and the annual confirmed cases of WNV in Romania was reported throughout this period [14]-[17]demonstrating reliability of such preventive measures of WNV infection.

In the light of the big epidemic that occurred in 2008 in Emilia-Romagna, Italy, Velati et al. [18] discusses the surveillance network that was proposed and run during the June-October period. The spatio-temporal characteristics of theprogram were embraced by fixed geographical stations where mosquitoes were collected overnight through $\mathrm{CO} 2$ baited traps. Before the PCR analysis, mosquitoes were counted, identified by species, and pooled by date and location with a maximum of 200 mosquitoes in thepool. This method was accompanied by veterinary surveillance on wild birds in the targeted area. Similar articles that speak towards mosquitoes and bird surveillance in Italy were identified [19]. The mentioned studies state that this typeof program brings extreme value in controlling WNV in the endemic areas and should be regularly operated.

The leading mosquito borne infection inIsrael is WNV [20] and data shows that after the 2000 outbreak a quite stringent approach toward WNV prevention was taken. Annual entomological surveillancewas implemented from 2000 until 2015, which was accomplished using CDC baited traps during the summer period in endemic zones of Israel [21], [22]. Meanwhile, another article was publishedstating that seroprevalence studies on horses in correlation with environmental factors were carried out [23]. 


\section{B. North America}

Canada has been affected by WNV activity which caused outbreaks in seven provinces: Ontario, Quebec, Manitoba, New Brunswick, Nova Scotia, Alberta and Saskatchewan. After the announcement of its first WNV case in 2000, Canada has consolidated forces and formed the Committee for West Nile Virus Surveillance to protect Canadians. The committee was established by thePublic Health Agency of Canada and activated at federal, provincial, and municipal levels [24]. The province of Ontario finds authority under the Health Protection and Promotion Act which mandates all the health units in the province to run WNV surveillance programs to mitigate the threat to the public, and strict compliance is expected [65]. Health Units in the province of Ontario follow a WNV SurveillanceControl and Prevention Framework which was established according to CDC recommendations and is based on the IVM approach. Because consistency isthe key factor for a successful program in WNV prevention and control which brings validity and accuracy in the long run, all health units in Ontario are religiously collecting data from mosquito traps and larval collection every summer.Hence, the health units can perform a riskassessment of a specific geographical area and elaborate history of annual virus activity trends. Furthermore, this consistent approach enhances the program's reliability and aids in planningtrustful strategies to combat the virus activity that works best for a specific zone. It is worth noting that each health unit performs annual assessments and reports about WNV cases and preventionmethods which are provided to the publicon each health unit website.

Dead bird collection (crows, jays, magpies, and ravens) was part of the initial approaches of the WNV program, which occurred to be a reliable indicator in detecting the virus that facilitated the course of mosquito control and viral prevention methods [24], [25]. Although the technique proved to be sensitive in identifying the $\mathrm{WNV}$, limitations related to expenses and accurate reports from the public occurred [24], therefore a more consistent and efficient method was put inplace over the years.

Due to climate particularities in South Ontario, with very warm and humid summers and sufficient precipitations throughout the year, this province hasreported the highest number of cases of WNV since 2000. Given the gravity of provincial WNV incidence, Ontario established the WNV Surveillance Control and Prevention Framework. There are 34 health units in the province of Ontario that deliver WNV surveillance programs in each jurisdiction and monitor the virus activity on an annual basis fromMay to October. Adult mosquito surveillance consists of light traps by CDC baited with ice. These traps are set on a weekly basis by the health unit staff in the areas where WNV cases are determined to be most prevalent and are collected the following day; the samples are sent to a Public Health Agency of Canada certified diagnostic laboratory to identify the mosquito species and test for WNV [26]. In the same study, it is mentioned that the Culex mosquito is the most prevalent species, and its prevalencewas strongly correlated with a high incidence of WNV cases in South Ontario. Giordano et al. [26] concludethat this type of mosquito surveillanceprogram plays a primordial role in determining the seasonal species, spatial distribution and high or low-risk areas; it also helps the health units in assessing theannual data to prepare a more efficient preventative system for the next season.

Another effective method of WNV control is practicing annual mosquito reduction through the larviciding program. This technique consists of using environmentally friendly larvicides (in the form of granules, briquets, or pellets)in the stagnant water of roadside catch basins in both rural and urban locations. The products are applied in three rounds, one month apart, and each treated catch basin is marked with a colour thatindicates the completed treatment [27].

Larvicides are also used on the surface water as a method of mosquito breeding control. Each summer, trained staff collects larvae from standing water near roadsides, ditches, nesting spaces stormwater ponds, marshes, and high vegetation areas that provide habitat for the vectors. The larvae collection is performed on a two $\mathrm{m}^{2}$ area using a long stick-cup for water sampling, an eyedropper, and a vial container to place the larvae. The larvae species and their stage of life are identified with an open eye, collected in the vial, and then kept ina cool bag to be transported to the health unit laboratory for microscopy analysis. A count of 1-6 larvae in a sample indicates a low-risk area, 7-30 indicates amedium risk area, and more than 31 larvae in a sample is a great indicator of the high probability of mosquito breeding and developing a new cycle in the next two weeks. Consequently, the medium and high-risk areas are being larvicide to stop the life cycle of mosquitoes and to prevent new breeding. The high-risk areasare followed up once a month andsampled to monitor the efficacy of treatment. At this point in time, the persistence of larvae in the standing waterensures the need for another round of treatment.

Informing the public and local stakeholders about the WNV surveillanceactivities is an important key in reinforcing preventative methods andkeeping the community updated. All the Health Units in Ontario create educational campaigns to deliver information about personal protection against mosquito bites and sourcereduction in the residential area and neighbourhood [25].

Manitoba, located at the North-West side of Ontario, has also been attacked by the WNV. To minimize the risk of transmission in the province, the Manitoban health authorities implemented a well-controlled WNVframework that carries out activities on a yearly basis. This framework is based on the Integrated Pest Management (IPM) plan and constitutes the following components: prevention, identification, response threshold, treatments, and evaluation [28]. The prevention element addresses personal protection issues, such as educating and encouraging the residents to take action against mosquito bites, as well as source reduction in the community and landscapingmodifications and infrastructure planning, which aims to reduce and remove the mosquito habitat and to improve the drainage areas. Identification interventions help to recognize the mosquitoes' habitat in specific areas and pinpoint locations where eggs would be laid. Mosquito population trends and the WNV activity levels are analyzed through data obtained from larval and adult monitoring, which incorporates larval

counting from a body of water dip, collecting adult mosquitoes by using CDC traps and testing them for WNV. Following this, the response threshold is met by counting the larvae in the dip andappreciating if this presents a threat to the 
public and requires treatment with larvicides. The effectiveness of the treatment is evaluated in 24-48 hours, where another dipping is performed, and a decision about the need for additional treatment is made. The treatment logs are ultimately analyzed for "hot spot" identification and utilized as a reference the following year.

WNV outbreaks have occurred in the province of Quebec as well, where cases with non-neurologic and neurologic symptoms were reported. Consequently, in 2016 the province implemented programs that were focusing on providing adequate entomological surveillance to lessen the risk of WNV transmission in the high-risk areas [29]. The province relies on active and passive mosquito surveillance. The active monitoring is based on the collection of adult populations of mosquitoes, using CDC light traps used in fixed entomological stations, while passive surveillance depends on the testing of wild birds and domestic animals, like horses [29].

New Brunswick is another province in Canada that has been affected by WNV which led the public health agencies to conduct epidemiological and surveillancestudies to control the virus. Both adult andlarval collection activities are carried out in this region, followed by larval treatment of high-risk areas [30].

Nova Scotia's climate conditions favour mosquito development which increases the risk of WNV transmission. Mosquitoes control measures are well established and involve interventions thatcollect adult and larval mosquitoes, testing for WNV and consecutivetreatments [31].

Although some places in Canada seemto have long and warm summers, thetemperatures are too low to satisfy the optimum conditions for mosquitoes'breeding and survival. Research on WNV transmission was conducted in Newfoundland, and it was found thatthough species that carry the WNVexisted in the area, the coolerenvironment would limit mosquitoes'ability to transmit the virus [32].

The first outbreak that marked the United States history was the 1999 outbreak in New York City [33]. Thisevent prompted the public health authorities to establish a vector surveillance program that was conducted every year. Numerous data demonstrate the dead bird surveillance was one of the first approaches to control the West Nile Virus in the states. Various data was found to describe the process and the importance of dead bird surveillance as anearly indicator of virus presence in an area [34]-[38]. While many states welcomed this method, its value has decreased over the years due to cost issues, a little report from the public, reduction of highly susceptible bird population, and lack of staff to perform collection, necropsy, and testing [38]. It isstated in the same study that consequently, mosquito surveillance gained more attention as it provides morequantitative and reliable data. Adult mosquito collection is carried out using light traps compressed with carbon dioxide by $\mathrm{CDC}$ and transported on dry ice, at a temperature of $-20^{\circ} \mathrm{C}$, to be identified and pooled by location, species, and date [37]. It is worth noting that climate change is a great contributor to the West Nile Virus outbreaks, and somestates like Texas are more affected in thiscontext. In 2012, Texas suffered the largest epidemic, which not only affected the incidence rate of WNV cases and mortality, but also it impacted the state's economy, vector control and work productivity [39]. The author of this article discusses the magnitude of thisevent and emphasizes how public health authorities had urged into creating new models of predicting the WSV as an early warning system for virus transmission. The new project, which is a long-term and systematic WNV surveillance, deploys the weekly use of a combination of two traps: storm sewer and gravid traps. The storm sewer traps are a modified version of CDC traps that are baited with ice and are connected to "man-hole covers underground to attract hostseekingmosquitoes". The gravid traps are baited with hay infusion water, and their main purpose is to capture the adult femalemosquitoes that are laying eggs; these traps are set under vegetation areas inresidential yards. It was observed that thestorm sewer traps were used as shelter orhibernacula by some mosquito species during the winter period, with a subsequent high abundance in the spring months. This project not only did study mosquito living patterns but also analyzed the factors that contributed to their thriving life; that is why the new model was proposed as a reliable control and prevention method for the West Nile virus.

\section{South America}

The WNV outbreaks that arose in the north side of the Americas had subsequently emerged to its south side and had put the public at risk of infection. Various epidemiological surveillancestudies have been proposed and conducted to better understand the characteristics of the virus in this geographic area, although no descriptive framework of control methods was found.In Colombia, particular attention was given to the serological detection of WNV in humans and horses, entomological analysis, and analysis of climatic factors as part of surveillance programs [40]. This article describes how adult mosquito sampling was performed, which involved the use of two CDC light traps and one Shanon light trap placed at $20 \mathrm{~m}$ apart from each other from dusk to dawn. Larva sampling included water collection from ponds, wetlands, lagoons, and swamps in the proximity of the adultcollection zone. The study discusses the relationship between the climate changes in Colombia, specifically the abundance of mosquitoes and invasive aquatic plants like Ludwigia Grandiflora, which are interconnected to the mosquito's habitat. Another important point to be mentioned is that because of the geographical positioning and the natural migration process of birds to the south side, Colombia might face more WNV outbreaks in future. Therefore, more consideration in this matter is suggested to decision-makers. To assess mosquitoes' morphological properties and their rates of WNV transmission inArgentina, Micieli et al. [41] collected egg drafts from artificial containers and drainage ditches in vials where tap water and ground guinea food was added and left the eggs to grow until they reached the fourthinstar larval stage. Morphological studies have been conducted in Brazil as well, where cases of WNV have been reported. Such studies were based on adult mosquito collection using CDC light traps and serological analysis of equines [42].

\section{Asia}

Even though WNV is more prevalent inEurope and North America, there are states in Asia where some cases havebeen reported, and it became a public health concern due to 
neurological issues that it can cause. Control methods programs similar to $\mathrm{CDC}$ recommendations were not identified.

Due to the lack of published epidemiological data, Sandhu et al. [43] question if a surveillance and control system is needed in Punjab, India. Reports of WNV in this region have been made, although no surveillance system has been developed. The author mentions that Punjab is highly populated by horseswhich are well known to be a WNV host. Therefore, a vaccination program in there animals would contribute to a solid control method of this viral infection. It isalso suggested that more public awareness on how the virus develops should be initiated along with a surveillance and larviciding program delivered by governmental bodies. In another study conducted in India, it was found that the serological element of WNV in domestic ducks is highly prevalent in areas where WNV human cases were reported, which urged the public health authorities to implement surveillance programs to prevent future outbreaks [44]. Mosquito serology studies are discussed in another article where samples were collected by asuction tube and flashlight; the result of this study indicated that one of the WNVstrains was persistent during the winter period, and more research in this matter was suggested [45].

Data from Iran outlines that cases of WNV have occurred over the years, but information on specific surveillance programs is quite limited. Nevertheless, data on adult mosquito collection was found, with slight details on samplingmethods- CDC light traps and, occasionally, manual aspirators [46]. These methods were carried every two weeks and set up in animal shelters from April to October to identify mosquitoes morphology. Adham et al. [47] appreciatethe seasonal activity of mosquitos by collecting the larva twice a month; this study was accompanied by climate observations too. The study demonstrated that larva abundance was significantly higher in regions with increased temperatures and more rainfalls.

A more active WNV surveillance systemwas noticed in Turkey, where a national mosquito investigation was put in place in2014-2015 from June to October [48].This study was intended to identify the mosquitoes' morphology by using Miniature Blacklights traps and CDC Miniature Light traps which were placed overnight at different locations and transferred to ice containers in the morning. Another sampling method mentioned in this study is utilizing Prokopack aspirators and Hepa filter mouth aspirators. These devices collected the adult mosquitoes from inside and outside residential areas where the vectors were most habituating. A similar study was conducted by Akıner et al. [49] a year later, where Prokopack and Hepa filter mouth aspirators were the main tools used for mosquito sampling.

Data shows that after the major outbreaks that occurred in Russia since 1999, an annual surveillance system was established and strictly followed during spring and summertime [50]. Thesurveillance methods relied on the use ofbackpack aspirators; samples were taken from indoor and outdoor collections fromboth rural and urban areas [50].

\section{E. Australia}

Australia was hit by an outbreak in 2011 that was caused by an Indigenous Kunjin-WNV strain [51]. Nevertheless, details onparticular WNV surveillance programs were not found, but rather studies about WNV virulence [51], [52], transmissibility [53] or introduction ofWNV via international flights [54]. To provide a gist of the study, van den Hurk et al. [52] briefly introduces the mosquitocollection method, which relates to CDC light traps baited with $\mathrm{CO} 2$.

\section{F. Africa}

Since Africa is the country where WNVoriginates, studies and surveillance programs have been conducted over the years to control the virus. Tunisia is one of the countries that faced several human epidemics, which resulted in severe damage to the central nervous system andmany cases of death. Therefore, publichealth authorities established programsthat aimed to collect adult mosquitoes in high-risk areas and detect WNV [55], [56]. CDC light traps operating from sunset to sunrise were the principal tool used for entomological sampling and analysis, which were placed near residential areas with positive cases, wetlands, and migratory bird settlement areas [55], [56]. Moreover, Monastiri et al. [56] state that this program also aimed to examine the serological aspect of WNV in humans and birds for a period oftwo years. Due to high WNV activity in Tunisia, control methods such as treatment with adulticides and larvicides were implemented on a yearly basis, along with preventive methods like wearing proper clothing, using repellents, and minimizing the exposure time during the high activity mosquito hours [56]. Nigeria also shows evidence of WNV activity, although more human serological studies than mosquito surveillance were documented with brief descriptions of some control methods, such as adulticiding and larviciding and bite prevention by using repellents [57]. Venter et al. [58] study the rapport between the human cases and horses, which could ultimately be used as an important indicator of WNV distribution in South Africa and the start of avaccination program in horses before an outbreak. The author of this study mentions that domestic animal surveillance is a valuable technique in detecting the virus in a geographic area, although cases of fatal encephalopathy in giraffes were reported, which as well suggests that the wildlife is more susceptible to the virus attack and focus on this animal population may be a morereliable early detection technique. Thisstatement is supported by another study that demonstrates that wild animals have a higher susceptibility for the virus and represent an essential WNV prediction method in Africa [59].

\section{Climate Change In ENDEMic Countries}

Climatic factors such as temperature, precipitation, wind, and relative humidityplay a major role in vector population dynamics and WNV replication rate within the vector. Although data shows that viral replication is possible at a temperature range of $14-45{ }^{\circ} \mathrm{C}$, it was noticed that higher temperature provides a more optimal condition for WNV replication [60]. Conversely, some mosquito activity seems to be negatively affected by heat conditions, provided that some larval growth and survival mode declined at temperatures above $30{ }^{\circ} \mathrm{C}$ [60], [61]. The precipitation element in the WNV activity and transmission area also brings important issues to discuss. 
While heavy rainfall can supply the standing water surfaces with enough water to ensure larval development, this can also neutralize the nutrient content and consequently reduce the larval multiplication rate; it can also clear out the drainage channels and ditches used asbreeding sites by some mosquitos [60]. Another important aspect is that viral host amplification is positively affected by drought, given the fact that some birds tend to populate the standing watersurfaces more often during such weather conditions, increasing the contact between vector and host [60]. The wind factor is remarkable through its impact on the virus spread. It was demonstrated thatsome mosquitos could be blown by wind which can cause further migration [60], [64].

\section{RESULTS AND DISCUSSION}

Our paper examines the endemic countries where WNV outbreaks have occurred over the years and propose efficient and effective strategies to develop a WNV program. Establishing aWNV program is the foremost key in the prevention and control of virustransmission, which requires strategies that are effective and efficient and tailored for specific geographical areas. To maximize the effectiveness of WNVcontrol, CDC recommends implementingprograms that imply vector surveillance,treatments with larvicides and adulticidesand public prevention education. Afteranalyzing the articles published byendemic countries, we deduce that manyof these do not entirely follow CDCguidance and/or published data is limited.It is noticed that some nations like Italy,Israel, Greece, Romania rely on birdsurveillance and serology analysis as themain method of control. A similar approach is seen in India, Iran, andRussia, although details about theseprograms are modest. It is noticed thatmost of the endemic countries set up CDC traps which are left overnight in the high- risk areas; however, handheld aspirators were observed to be used by countrieslike Romania and Russia. Informationabout larva collection and treatment isvery sparse; only a couple of articlespublished in Italy and Tunisia providedinformation in this matter. Nevertheless,abundant data about vector surveillance,larval collection and control and preventing methods was observed in the WNV activity and farther mosquito development.

\section{A. Mosquito Surveillance}

This intervention needs to be implemented during the May-October months, which implicates setting up CDCtraps overnight. The surveillance must becarried out consistentlyweekly, seasonally, and annually. Data collected from the traps will help identify the presence of the virus, as well as trends ofmosquito count/abundance and species, which can be used to create maps with high-risk areas for the next season.

\section{B. Larval Surveillance}

Larvae surveillance of standing water near roadsides, ditches, nesting spaces, stormwater ponds, and marches.

\section{Serology Testing}

Perform serological essays on birds to detect WNV antibodies. This method maybe especially beneficial for the endemic countries where WNV prevails in rural areas, where chickens are more frequentlyraised.

\section{Larvicide Treatment}

Treatment of medium and high-risk areas(standing water and catch-basins) to stop larvae from emerging into adult form andprevent new breeding.

\section{E. Treatment Monitoring}

Monitor the larviciding efficacy 2-3weeks after treatment application. Apply a subsequent treatment when necessary.

\section{F. Prevention}

Increase community awareness on WNV activity, source reduction and self- protection. Create campaigns, videos, podcasts, flyers in a format that would attract attention and increase interest for each age group in the community and explain the gravity of WNV and its risks on people's health. Encourage thecommunity members to participate in source reduction by regularly clearing the standing water in trash containers, tires, toys, rain gutters, paddling pools, flowers pots and buckets. Provide education on avoiding outdoor activities during mosquito high activity hours in high-risk areas and practicing personal protection in schools, universities, communities, andhealth-care centers.

\section{CONCLUSION}

Our paper examines strategies applied in controlling WNV in endemic countriesaround the world and identifies the most efficient and effective strategies to develop a WNV program. It is clear fromthe review that not many countries have these strategies documented in research papers or national protocols. Most of the research found referred to general WNV surveillance studies along with birds and human seropositivity rather than control and prevention program documentation.

One of the limitations of the paper is the lack of WNV program details and WNV data for some countries in Africa, Asia, and Europe, as we encounteredchallenges in accessing this information. The paper aims to fill the gap in the literature regarding the framework for WNV control and prevention programs. Our proposed model may be adopted by countries where the current strategies areless effective.

\section{REFERENCES}

[1] World Health Organisation. (October 2017). West Nile Virus. Key Facts. https://www.who.int/news-room/fact- sheets/detail/west-nilevirus.

[2] Nasci, R. S., Fischer, M., Lindsey, N. P., Lanciotti, R. S., Savage, H. M., Komar, N., McAllister, J. C., Mutebi, J-P., Lavelle, J, M.,ZielinskiGutierrez, E., and Petersen, L. P. (June 2013). West Nile Virus in the United States: Guidelines for Surveillance, Prevention and Control. Resource document. Center for Disease Control and Prevention. Division of Vector-Borne Diseases. https://www.cdc.gov/westnile/resources/pdfs/wnvGuidelines.pdf.

[3] Reed, L. M., Johansson, M. A., Panella, N., McLean, R., Creekmore, T., Puelle, R., \& Komar, N. (2009). Declining mortality in American crow (corvus brachyrhynchos) following natural west nile virus infection. Avian Diseases, 53(3), 458- 461. https://doi.org/10.1637/8468-091208-ResNote.1.

[4] Patnaik, J. L., Juliusson, L., \& Vogt, R. L. (2007). Environmental predictors of human west nile virus infections, colorado. Emerging Infectious $\quad$ Diseases, $13(11), \quad 1788-1790$. https://doi.org/10.3201/eid1311.070506. 
[5] Enviornmental Protection Agency. (n.d.). Controlling Adult Mosquitoes. United States.

https://www.epa.gov/mosquitocontrol/controlling-adult- mosquitoes.

[6] Sirbu, A., Popovici, F., Pistol, A., Serban, R., Pitigoi, D., Posea,C., Ceianu, C., Nicolescu, G., Bellini, R., Coulombier, D.,Depoortere, E. Domanovic, D., Herrador, Z., Leitmeyer, K.,Lenglet, A., Marrama, L., Rehmet, S., Robinson, E., Santos O.C,F., Bortel, W. V., Warns, P. E., and Zeller, H. (July 2013).Technical report. West Nile Virus Risk Assessment tool. Resource document. European Center for Disease Prevention andControl.

https://www.ecdc.europa.eu/sites/default/files/media/en/publicat ions/Publications/west-nile-virus-risk-assessment-tool.pdf.

[7] Patsoula, E., Vakali, A., Balatsos, G., Pervanidou, D., Beleri, S., Tegos, N., Baka, A., Spanakos, G., Georgakopoulou, T., Tserkezou, P., Van Bortel, W., Zeller, H., Menounos, P., Kremastinou, J., and Hadjichristodoulou, C. (2016). West Nile Viruse Circulation in Mosquitoes in Greece (2010-2013), BioMed research international, 2016, 2450682. https://doi.org/10.1155/2016/2450682.

[8] Chaintoutis, S. C., Chaskopoulou, A., Chassalevris, T., Koehler, P. G., Papanastassopoulou, M., and Dovas, C. I. (2013). West Nile virus lineage 2 strain in Greece, 2012. Emerging infectious diseases, 19(5), 827-829. https://doi.org/10.3201/eid1905.121418.

[9] Chaskopoulou, A., Dovas, C. I., Chaintoutis, S. C., Kashefi, J., Koehler, P., and Papanastassopoulou, M. (2013). Detection and early warning of West Nile Virus circulation in Central Macedonia, Greece, using sentinel chickens and mosquitoes. Vector borne and zoonotic diseases (Larchmont, N.Y.), 13(10), 723-732. https://doi.org/10.1089/vbz.2012.1176.

[10] Chaintoutis, S. C., Dovas, C. I., Danis, K., Gewehr, S., Mourelatos, S., Hadjichristodoulou, C., and Papanastassopoulou, M. (2015). Surveillance and early warning of west nile virus lineage 2 using backyard chickens and correlation to human neuroinvasive cases. Zoonoses and Public Health, 62(5), $344 \quad 355$ https://doi.org/10.1111/zph.12152.

[11] Chaintoutis, S. C., Gewehr, S., Mourelatos, S., and Dovas, C. I. (2016). Serological monitoring of backyard chickens in central macedoniagreece can detect low transmission of west nile virus in the absence of human neuroinvasive disease cases. Acta Tropica, 163, 26-31. https://doi.org/10.1016/j.actatropica.2016.07.018.

[12] Chaintoutis, S. C., Dovas, C. I., Papanastassopoulou, M., Gewehr, S., Danis, K., Beck, C., Lecollinet, S., Antalis, V., Kalaitzopoulou, S., Panagiotopoulos, T., Mourelatos, S., Zientara, S., and Papadopoulos, O. (2014). Evaluation of a west nile viruse surveillance and early warning system in greece, based on domestic pigeons. Comparative Immunology, Microbiology and Infectious Diseases, 37(2), 131-141. https://doi.org/10.1016/j.cimid.2014.01.004.

[13] Ceianu, C. S., Ungureanu, A., Nicolescu, G., Cernescu, C., Nitescu, L., Tardei, G., Petrescu, A., Pitigoi, D., Martin, D., Ciulacu-Purcarea, V., Vladimirescu, A., and Savage, H. M. (2001). West nile virus surveillance in romania: 1997-2000. ViralImmunology, 14(3), 251-262. https://doi.org/10.1089/088282401753266765.

[14] Campbell, G. L., Ceianu, C. S., and Savage, H. M. (2001). Epidemic West Nile encephalitis in Romania: waiting for historyto repeat itself. Annals of the New York Academy of Sciences, 951, 94-101.

[15] Tomazatos, A., Jansen, S., Pfister, S., Török, E., Maranda, I., Horváth, C., Keresztes, L., Spînu, M., Tannich, E., Jöst, H., Schmidt-Chanasit, J., Cadar, D., and Lühken, R. (2019). Ecologyof west nile virus in the danube delta, romania: Phylogeography, xenosurveillance and mosquito host-feeding patterns. Viruses, 11(12), 1159 https://doi.org/10.3390/v11121159.

[16] Nicolescu, G. M., Ciulacu, V. S. P., Vladimirescu, A., Coipan, E.C., Petrisor, A. I., Dumitrescu, G., Saizu, D., Savin, E., Sandric, I., and Mihai, F. (2016). Emergence risk and surveillance of westnile virus infections in romania. International Journal of Infectious Diseases, 53, 158-159. https://doi.org/10.1016/j.ijid.2016.11.387.

[17] Velati, C., Angelini, P., and Pupella, S. (2017). State of the art: Vest Nile Virus circulation surveillance in Italy and transfusion risk early prevention methods. Transfusion clinique et biologique: journal de la Societe francaise de transfusion sanguine, 24(3), 172-175. https://doi.org/10.1016/j.tracli.2017.06.019.

[18] Bellini, R., Calzolari, M., Mattivi, A., Tamba, M., Angelini, P., Bonilauri, P., Albieri, A., Cagarelli, R., Carrieri, M., Dottori, M., Finarelli, A., Gaibani, P., Landini, M., Natalini, S., Pascarelli, N., Rossini, G., Velati, C., Vocale, C., and Bedeschi, E. (2014). The experience of west nile virus integrated surveillance system in theemiliaromagna region: Five years of implementation, italy, 2009to 2013. Euro Surveillance: Bulletin Européen Sur Les Maladies Transmissibles, 19(44), 20953.

https://doi.org/10.2807/1560- 7917.ES2014.19.44.20953.
[19] Salama, M., Amitai, Z., Lustig, Y., Mor, Z., Weiberger, M., Chowers, M., Maayan, S., Zimhony, O., Ben-Ami, R., Chazan, B., ZaltzmanBershadsky, N., Cohen, R., Tsyba, E., Sheffer, R., Anis, E., Glazer, Y., Pessah, S., Mendelson, E., and Leshem, E. (2019). Outbreak of west nile virus disease in israel (2015): A retrospective analysis of notified cases. Travel Medicine and Infectious Disease, 28, 41-45. https://doi.org/10.1016/j.tmaid.2018.07.008.

[20] Lustig, Y., Hindiyeh, M., Orshan, L., Weiss, L., Koren, R., KatzLikvornik, S., Zadka, H., Glatman-Freedman, A., Mendelson, E., and Shulman, L. M. (2016). Mosquito surveillance for 15 years reveals high genetic diversity among west nile viruses in israel. The Journal of Infectious Diseases, 213(7), 1107-1114. https://doi.org/10.1093/infdis/jiv556.

[21] Lustig, Y., Kaufman, Z., Mendelson, E., Orshan, L., Anis, E., Glazer, Y., Cohen, D., Shohat, T., and Bassal, R. (2017). Spatialdistribution of west nile virus in humans and mosquitoes in israel, 2000-2014. International Journal of Infectious Diseases, 64, 20- 26. https://doi.org/10.1016/j.ijid.2017.08.011.

[22] Aharonson-Raz, K., Lichter-Peled, A., Tal, S., Gelman, B., Cohen, D., Klement, E., and Steinman, A. (2014). Spatial and temporal distribution of west nile virus in horses in israel (1997-2013)-from endemic to epidemics. PloS One, 9(11), e113149- e113149. https://doi.org/10.1371/journal.pone.0113149.

[23] Shuai, J., Buck, P., Sockett, P., Aramini, J., and Pollari, F. (2006).A GISdriven integrated real-time surveillance pilot system for national West Nile virus dead bird surveillance in Canada. International journal of health geographics, 5, 17. https://doi.org/10.1186/1476-072X-5-17.

[24] Government of Canada. (February 2021). Surveillance of WestNile Virus. https://www.canada.ca/en/public-health/services/diseases/westnile-virus/surveillance-west-nile- virus.html.

[25] Giordano, B. V., Kaur, S., and Hunter, F. F. (2017). West Nile virus in Ontario, Canada: A twelve-year analysis of human case prevalence, mosquito surveillance, and climate data. PloS one, 12(8), e0183568. https://doi.org/10.1371/journal.pone.0183568.

[26] Region of Peel. (July 2017). Mosquitoes and tick-borne diseases Larviciding. https://www.peelregion.ca/health/vbd/larviciding.htm.

[27] Integrated Pest Management Guide. (2016). Integrated Pest Management. Quick Guide for Provincial Cost-Share Participants. Resource document. Government of Manitoba. https://www.gov.mb.ca/health/wnv/docs/ipm_costshare.pdf.

[28] Institute National De Sante Publique du Quebec. (May 2016).Report on Surveillance of the West Nile Virus and otherArboviruses in Quebec: 2016 Season. Resource document. https://www.inspq.qc.ca/sites/default/files/publications/2416_re port_surveillance_west_nile_virus_other_arboviruses_2016.pdf.

[29] Webster, P. R., Giguere, M. A., Maltais, P., Roy, J., Gallie, L., and Edsal, J. (January 2004). Survey of the mosquitoes of NewBrunswick. Government of New Brunswick. Resource document https://www2.gnb.ca/content/dam/gnb/Departments/hs/pdf/en/CDC/MosquitoeSurvey.pdf.

[30] Nova Scotia. (May 2003). Nova Scotia Prepares for West NileVirus Season. https://novascotia.ca/news/release/?id=20030508002.

[31] Department of Natural Resources Animal Health Division. (2010,May). West Nile Virus Surveillance. Resource document. Newfoundland Labrador. https://www.gov.nl.ca/ffa/files/agrifoods-animals-healthpdf-ds-08-002.pdf. Accessed 14 April 2021.

[32] Nash, D., Mostashari, F., Fine, A., Miller, J., O'Leary, D., Murray, K., Huang, A., Rosenberg, A., Greenberg, A.,Sherman, M., Wong, S., Layton, M., and 1999 West Nile Outbreak Response Working Group (2001). The outbreak of West Nile virus infection in the New York City area in 1999. The New England journal of medicine, 344(24), 18071814.https://doi.org/10.1056/NEJM200106143442401

[33] Eidson, M., Miller, J., Kramer, L., Cherry, B., Hagiwara, Y., andWest Nile Virus Bird Mortality Analysis Group (2001). Dead crow densities and human cases of West Nile virus, New York State, 2000. Emerging infectious diseases, 7(4), 662-664. https://doi.org/10.3201/eid0704.010411.

[34] Julian, K. G., Eidson, M., Kipp, A. M., Weiss, E., Petersen, L. R.,Miller, J. R., Hinten, S. R., and Marfin, A. A. (2002). Early season crow mortality as a sentinel for West Nile virus disease in humans, northeastern United States. Vector borne and zoonotic diseases (Larchmont, N.Y.), 2(3), 145-155. https://doi.org/10.1089/15303660260613710.

[35] Carney, R. M., Ahearn, S. C., McConchie, A., Glasner, C., Jean,C., Barker, C., Park, B., Padgett, K., Parker, E., Aquino, E., and Kramer, V. (2011). Early warning system for west nile virus risk areas, california, USA. Emerging Infectious Diseases, 17(8), 1445-1454 https://doi.org/10.3201/eid1708.100411.

[36] Friesen, K. M., and Johnson, G. D. (2014). Mosquito and west nile virus surveillance in northeast montana, U.S.A., 2005 and 2006 : 
Mosquito and west nile virus surveillance. Medical and Veterinary Entomology, 28(1), 85-93. https://doi.org/10.1111/mve.12011.

[37] Petersen L. R. (2019). Epidemiology of West Nile Virus in the United States: Implications for Arbovirology and Public Health. Journal of medical entomology, 56(6), 1456-1462. https://doi.org/10.1093/jme/tjz085.

[38] Poh, K. C., Chaves, L. F., Reyna-Nava, M., Roberts, C. M., Fredregill, C., Bueno, R., Debboun, M., and Hamer, G. L. (2019). The influence of weather and weather variability on mosquito abundance and infection with West Nile virus in Harris County, Texas, USA. Science of The Total Environment, 675(Complete),260-272. https://doi.org/10.1016/j.scitotenv.2019.04.109.

[39] Diana P. Barajas P, Karl A. Ciuoderis A, G, D. C., O, A. G., B, J.O., Camilo E. Pacheco P, Nestor I. Monroy O, and Gloria D Tovar B. (2020). Epidemiological surveillance of west nile virusin the eastern plains of colombia. Revista MVZ Córdoba, 25(1), e1252.

[40] Micieli, M. V., Matacchiero, A. C., Muttis, E., Fonseca, D. M., Aliota, M. T., and Kramer, L. D. (2013). Vector competence of Argentine mosquitoes (Diptera: Culicidae) for West Nile virus (Flaviviridae:Flavivirus). Journal of medical entomology, 50(4), 853862. https://doi.org/10.1603/me12226.

[41] Pauvolid-Corrêa, A., Morales, M. A., Levis, S., Figueiredo, L. T.M., Couto-Lima, D., Zilca, C., Nogueira, M. F., da Silva, E. E., Nogueira, R. M. R., and Schatzmayr, H. G. (2011). Neutralising antibodies for west nile virus in horses from brazilian pantanal. Memórias do Instituto Oswaldo Cruz, 106(4), 467-474. https://doi.org/10.1590/S0074-02762011000400014.

[42] Sandhu, T. S., Sidhu, D. S., and Sandhu, G. K. (2010). West nilevirus: do we need its surveillance and control program in punjab state of India?. Indian journal of community medicine: official publication of Indian Association of Preventive \& Social Medicine, 35(2), 211-213. https://doi.org/10.4103/0970- 0218.66856.

[43] Kalaiyarasu, S., Mishra, N., Khetan, R. K., and Singh, V. P. (2016). Serological evidence of widespread West Nile virus and Japanese encephalitis virus infection in native domestic ducks (Anas platyrhynchos var domesticus) in Kuttanad region, Kerala, India Comparative immunology, microbiology and infectious diseases, 48, 61-68. https://doi.org/10.1016/j.cimid.2016.08.002.

[44] Khan, S. A., Kakati, S., Chowdhury, P., and Dutta, P. (2016). West Nile Virus circulation and incrimination of mosquito vectors in Northeast India. International Journal of Infectious Diseases, 45(Supplement 1), 179-179.https://doi.org/10.1016/j.ijid.2016.02.420.

[45] Azari-Hamidian, S., Norouzi, B., Noorallahi, A., and Ali Hanafi-Bojd, A. $(2018 ; 2019 ;)$. Seasonal activity of adult mosquitoes (diptera: Culicidae) in a focus of dirofilariasis and west nile infection in northern iran. Journal of Arthropod-Borne Diseases, 12(4), 398-413. https://doi.org/10.18502/jad.v12i4.358.

[46] Adham, D., Moradi-Asl, E., Vatandoost, H., and Saghafipour, A. (2019). Ecological Niche Modeling of West Nile Virus Vector in Northwest of Iran. Oman medical journal, 34(6), 514-520. https://doi.org/10.5001/omj.2019.94.

[47] Ergünay, K., Litzba, N., Brinkmann, A., Günay, F., Sarıkaya, Y.,Kar, S., Örsten, S., Öter, K., Domingo, C., Erisoz Kasap, Ö., Özkul, A., Mitchell, L., Nitsche, A., Alten, B., and Linton, Y.-M.(2017). Cocirculation of West Nile virus and distinct insect- specific flaviviruses in Turkey. Parasites \& Vectors, 10. https://doi.org/10.1186/s13071017-2087-7.

[48] Akıner, M. M., Öztürk, M., Başer, A. B., Günay, F., Hacıoğlu, S., Brinkmann, A., Emanet, N., Alten, B., Özkul, A., Nitsche, A., Linton, Y., and Ergünay, K. (2019). Arboviral screening of invasive aedes species in northeastern turkey: West nile virus circulation and detection of insect-only viruses. PLoS Neglected Tropical Diseases, 13(5), e0007334-e0007334. https://doi.org/10.1371/journal.pntd.0007334.

[49] Fyodorova, M. V., Savage, H. M., Lopatina, J. V., Bulgakova, T.A., Ivanitsky, A. V., Platonova, O. V., and Platonov, A. E. (2006). Evaluation of potential west nile virus vectors in volgograd region, russia, 2003 (diptera: Culicidae): Species composition, bloodmeal host utilization, and virus infection rates of mosquitoes. Journal of Medical Entomology, 43(3), 552-563. https://doi.org/10.1093/jmedent/43.3.552

[50] Prow, N. A., Edmonds, J. H., Williams, D. T., Setoh, Y. X., BielefeldtOhmann, H., Suen, W. W., Hobson-Peters, J., van denHurk, A. F., Pyke, A. T., Hall-Mendelin, S., Northill, J. A., Johansen, C. A., Warrilow, D., Wang, J., Kirkland, P. D., Doggett, S., Andrade, C. C., Brault, A. C., Khromykh, A. A., andHall, R. A. (2016). Virulence and Evolution of West Nile Virus, Australia, 1960-2012. Emerging infectious diseases, 22(8), 1353-1362. https://doi.org/10.3201/eid2208.151719.

[51] van den Hurk, A.F., Hall-Mendelin, S., Webb, and C.E. Role of enhanced vector transmission of a new West Nile virus strain in an outbreak of equine disease in Australia in 2011. Parasites Vectors 7, 586 (2014). https://doi.org/10.1186/s13071-014-0586-3.

[52] Hall-Mendelin, S., McLean, B. J., Bielefeldt-Ohmann, H., HobsonPeters, J., Hall, R. A., and van den Hurk, A. F. (2016). The insectspecific Palm Creek virus modulates West Nile virus infection in and transmission by Australian mosquitoes. Parasites \& Vectors, 9. https://doi.org/10.1186/s13071-016-1683-2.

[53] Hernández-Jover, M., Roche, S., and Ward, M. P. (2013). The human and animal health impacts of introduction and spread of an exotic strain of West Nile virus in Australia. Preventive Veterinary Medicine, 109(3-4), 186-204.https://doi.org/10.1016/j.prevetmed.2012.09.018.

[54] Wasfi, F., Dachraoui, K., Cherni, S., Bosworth, A., Barhoumi, W., Dowall, S., Chelbi, I., Derbali, M., Zoghlami, Z., Beier, J. C., and Zhioua, E. (2016). West Nile virus in Tunisia, 2014: First isolation from mosquitoes. Acta Tropica, 159(Complete), 106- 110. https://doi.org/10.1016/j.actatropica.2016.03.037.

[55] Monastiri, A., Mechri, B., Vázquez-González, A., Ar Gouilh, M., Chakroun, M., Loussaief, C., Mastouri, M., Dimassi, N., Boughzala, L., Aouni, M., and Serra-Cobo, J. (2018;2019;). A four-year survey (2011-2014) of west nile virus infection in humans, mosquitoes and birds, including the 2012 meningoencephalitis outbreak in tunisia. Emerging Microbes \& Infections, 7(1), 1-10. https://doi.org/10.1038/s41426-018-0028- y.

[56] Kolawole, O. E., and Kola, O. J. (2015). West Nile Virus Infection in Ogbomoso: Serological Evidence. Journal of Immunoassay and $\begin{array}{llr}\text { Immunochemistry, } & 36(6), & 573-578 .\end{array}$ https://doi.org/10.1080/15321819.2015.1017105.

[57] Venter, M., Pretorius, M., Fuller, J. A., Botha, E., Rakgotho, M., Stivaktas, V., Weyer, C., Romito, M., and Williams, J. (2017). West nile virus lineage 2 in horses and other animals with neurologic disease, south africa, 2008-2015. Emerging InfectiousDiseases, 23(12), 20602064. https://doi.org/10.3201/eid2312.162078

[58] Steyn, J., Botha, E., Stivaktas, V. I., Buss, P., Beechler, B. R., Myburgh, J. G., Steyl, J., Williams, J., and Venter, M. (2019). West Nile Virus in Wildlife and Nonequine Domestic Animals, South Africa, 2010-2018. Emerging infectious diseases, 25(12), 2290-2294. https://doi.org/10.3201/eid2512.190572.

[59] Paz S. (2015). Climate change impacts on West Nile virus transmission in a global context. Philosophical transactions of the Royal Society of London. Series B, Biological sciences, 370(1665), 20130561. https://doi.org/10.1098/rstb.2013.0561.

[60] Chen, C. C., Jenkins, E., Epp, T., Waldner, C., Curry, P. S., and Soos, C. (2013). Climate change and West Nile virus in a highly endemic region of North America. International journal of environmental research and public health, 10(7), 3052-3071. https://doi.org/10.3390/ijerph10073052.

[61] Mackenzie, J. S., Gubler, D. J., and Petersen, L. R. (2004). Emerging flaviviruses: the spread and resurgence of Japanese encephalitis, West Nile and dengue viruses. Nature medicine, 10 (12 Suppl), S98-S109. https://doi.org/10.1038/nm1144.

[62] Ozdenerol, E., Taff, G. N., and Akkus, C. (2013). Exploring the spatiotemporal dynamics of reservoir hosts, vectors, and humanhosts of West Nile virus: a review of the recent literature. International journal of environmental research and public health, 10(11), 5399-5432. https://doi.org/10.3390/ijerph10115399.

[63] Paz, S., Malkinson, D., Green, M. S., Tsioni, G., Papa, A., Danis,K., Sirbu, A., Ceianu, C., Katalin, K., Ferenczi, E., Zeller, H., andSemenza, J. C. (2013). Permissive summer temperatures of the 2010 european west nile fever upsurge. PloS One, 8(2), e56398- e56398. https://doi.org/10.1371/journal.pone.0056398.

[64] Health Protection and Promotion Act. R.S.O. 1990, c. H.7. O. Reg. 199/03: CONTROL OF WEST NILE VIRUS. https://www.ontario.ca/laws/regulation/030199.

Annual epidemiological report for 2019. (March 2021). WestNile Virus Infection. Resource document. European Center forDisease Control and Prevention. https://www.ecdc.europa.eu/sites/default/files/documents/AERWNV-infection-2019.pdf. 